\title{
ALK Rearrangement in Keratinizing Squamous Cell Lung Carcinoma: Immunohistochemistry of ALK-protein as a Convenient ALK Screening
}

Yusuke Takanashi ${ }^{*}$, Shogo Tajima ${ }^{2}$, Takamitsu Hayakawa ${ }^{1}$, Tsuyoshi Takahashi ${ }^{1}$, Hiroshi Neyatani ${ }^{1}$ and Kazuhito Funai ${ }^{3}$

${ }^{1}$ Department of Thoracic Surgery, Fujieda Municipal General Hospital, Fujieda, Japan

${ }^{2}$ Department of Pathology, University of Tokyo, Graduate School of Medicine, Tokyo, Japan

${ }^{3}$ Department of Surgery, Hamamatsu University School of Medicine, Hamamatsu, Japan

Keywords: Anaplastic lymphoma kinase; Squamous cell lung carcinoma; Immunohistochemistry

\section{Introduction}

Fusion of the anaplastic lymphoma kinase (ALK) gene with the echinoderm microtubule-associated protein-like 4 (EML4) gene has been identified as having a prevalence of approximately $5 \%$ in Japanese patients with non-small cell lung cancer (NSCLC), primarily adenocarcinoma [1]. Indeed, ALK-fusion is rarely observed in histologic types of lung cancer other than adenocarcinoma. This fusion gene is commonly seen in a younger age group of never or previous light smokers [2].

We experienced a rare case of an older man, with a heavy smoking history, who presented with ALK-positive keratinizing pure squamous cell carcinoma (SqCC) of the lung [3]. We here present the key points of this particular case, specifically the clinicopathologic details and clinical significance.

\section{Case}

A 60-year-old man, who was a previous tobacco smoker of 80 pack years, was noted to have a mass lesion measuring $32 \mathrm{~mm} \times 28$ $\mathrm{mm}$ in the left upper lobe on chest computed tomography (CT) [3]. Confirmation of the histologic type was difficult on routine pathologic examination due to the small transbronchial biopsy (TBB) specimens from the mass. Immunohistochemistry (IHC) was positive for P63, P40, and CK5/6, but negative for TTF-1; therefore, a diagnosis of lung SqCC was supported. Unexpectedly, on molecular analysis, the tumor was proven to be positive for ALK rearrangement by fluorescent insitu hybridization (FISH) [3] and negative for epidermal growth factor receptor (EGFR) mutation by polymerase chain reaction (PCR). Radiological work-up detected no apparent lymph node and distant metastasis.

Thereafter, the patient underwent left upper lobectomy for SqCC lung cancer cT2aN0M0. Hematoxylin and eosin (H\&E) staining of the surgical specimen demonstrated the typical morphology of moderately differentiated keratinized SqCC, specifically eosinophilic foci of intracellular keratinization and intercellular bridges around tumor cells (Figure 1A). The entire tumor consisted of pure SqCC and contained no component of adenocarcinoma or other histologic types. Repeat IHC analysis showed heterogeneously positive ALK-protein (Figure 1B) in all areas of the tumor. Based on a pathological stage of pT2aN0M0, the patient was given adjuvant chemotherapy with $250 \mathrm{mg} / \mathrm{m}^{2}$ of uracil-tegafur (UFT) and was advised to attend regular check-ups for postoperative recurrence.

\section{This particular case conveyed the following clinical messages:}

1. ALK rearrangement may exist in some heavy smokers who develop keratinizing pure SqCC of the lung, although the population may be small.

2. Detection of ALK protein by IHC may be useful for ALK screening of lung SqCC because of its low cost and convenience.
This case showed that ALK rearrangement may exist in keratinizing pure SqCC of the lung, although they are rarely identified in daily clinical practice. To date, only a few studies have addressed the varying frequency (1.4\% to $2.5 \%$ ) of EML4-ALK fusion genes detected by FISH in $\mathrm{SqCC}$ of the lung [4,5]. Moreover, previous detailed descriptions of the clinicopathologic features of lung SqCC with ALK rearrangement have been few $[2,3,6-8]$. We seldom have the opportunity to identify ALK-rearranged lung SqCCs probably because ALK testing was not recommended by the National Comprehensive Cancer Network (NCCN) guidelines as a routine in patients with lung SqCCs [9]. In the NCCN guidelines, ALK testing using FISH, which is the gold standard for ALK screening, remains only as a considerable option for SqCCs, especially in never-smokers, for small biopsy specimens, or for cancers with mixed histology, including adenosquamous cell carcinomas. At the moment, the low prevalence of ALK rearrangement does not justify routine testing of all tumor specimens. In the current case that was difficult to diagnose because of the small amount of TBB specimen, subsequent IHC and molecular analysis, including ALK testing, unexpectedly resulted in identification of ALK-positive SqCC.

Rare ALK fusion partners other than EML4-ALK, such as TFGALK and KIF5B-ALK, have been reported in NSCLCs [10]. In our case, breakage of the single-probe ALK during FISH testing precluded detailed subtyping of ALK fusion genes. EML4-ALK fusion genes remain

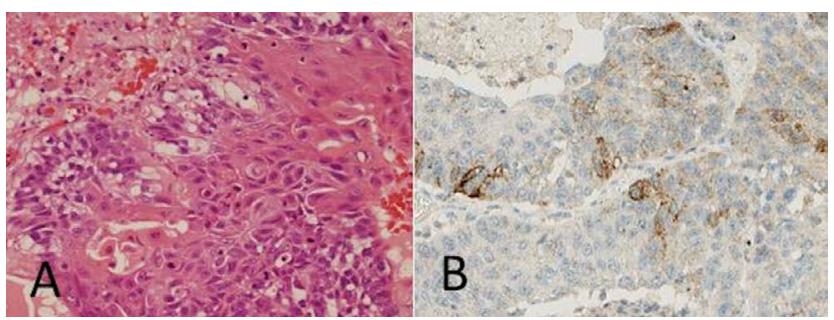

Figure 1: Photomicrograph of the resected squamous cell carcinoma specimen in a 60-year-old man with prior heavy smoking history. A) Routine histopathology shows the typical morphologic features of keratinizing SqCC (Hematoxylin and eosin stain, 400x). B) Immunohistochemistry is positive for ALK-protein (400x). SqCC; Squamous Cell Carcinoma; ALK: Anaplastic Lymphoma Kinase.

*Corresponding author: Yusuke Takanashi, Department of Thoracic Surgery, Fujieda Municipal General Hospital, 4-1-11 Surugadai, Fujieda-426-8677, Shizuoka Japan, Tel: +81-54-646-1111; Fax: +81-54-646-1114; E-mail: nashimed@yahoo.co.jp

Received January 09, 2016; Accepted January 18, 2016; Published January 22, 2016

Citation: Takanashi Y, Tajima S, Hayakawa T, Takahashi T, Neyatani $\mathrm{H}$, et al (2016) ALK Rearrangement in Keratinizing Squamous Cell Lung Carcinoma: Immunohistochemistry of ALK-protein as a Convenient ALK Screening. J Pulm Respir Med 6: 316. doi:10.4172/2161-105X.1000316

Copyright: @ 2016 Takanashi Y, et al. This is an open-access article distributed under the terms of the Creative Commons Attribution License, which permits unrestricted use, distribution, and reproduction in any medium, provided the original author and source are credited. 
Citation: Takanashi Y, Tajima S, Hayakawa T, Takahashi T, Neyatani H, et al. (2016) ALK Rearrangement in Keratinizing Squamous Cell Lung Carcinoma: Immunohistochemistry of ALK-protein as a Convenient ALK Screening. J Pulm Respir Med 6: 316. doi:10.4172/2161-105X.1000316

Page 2 of 3

\begin{tabular}{|c|c|c|c|c|c|c|c|c|}
\hline Reference & Age & Sex & Smoking status & $\begin{array}{l}\text { Sampling } \\
\text { method }\end{array}$ & Specimen & Histology & $\begin{array}{l}\text { ALK-protein } \\
\text { expression on } \\
\text { IHC }\end{array}$ & Response to crizotinib \\
\hline Alrifai et al. [2] & 69 & M & $\begin{array}{l}\text { Previous-smoker } \\
40 \text {-packs-per- } \\
\text { year }\end{array}$ & TBB & Primary tumor & Keratinizing SqCC & Unknown & Not administered \\
\hline Wang et al. [6] & 55 & $\mathrm{~F}$ & Never-smoker & Surgery & $\begin{array}{l}\text { Cervical lymph } \\
\text { node }\end{array}$ & Keratinizing SqCC & Positive & PR \\
\hline Zhang et al. [8] & 55 & $\mathrm{~F}$ & Never-smoker & TBB & Primary tumor & Keratinizing SqCC & Positive & PR \\
\hline Takanashi et al. [3] & 60 & M & $\begin{array}{l}\text { Previous-smoker } \\
720 \text {-packs-per- } \\
\text { year }\end{array}$ & Surgery & Primary tumor & Keratinizing SqCC & Positive & Not administered \\
\hline Vergne et al. [7] & 58 & $\mathrm{~F}$ & Never-smoker & TBB & Primary tumor & $\begin{array}{l}\text { Non-keratinizing } \\
\text { SqCC }\end{array}$ & Positive & PR \\
\hline
\end{tabular}

Table 1: Clinicopathologic characteristics of previously reported cases of ALK-rearranged lung SqCC. TBB: Transbronchial Biopsy; Sqcc: Squamous Cell Carcinoma; ALK: Anaplastic Lymphoma Kinase; PR: Partial Response.

the most popular coupling pattern among the ALK rearrangements, but this was not confirmed in our case.

\section{ALK rearrangement may exist in keratinizing pure SqCC with heavy smoking history and in non-keratinized type without a smoking history}

Although a certain percentage of ALK-rearranged adenocarcinomas are known to have characteristic morphologic features on histopathology, such as solid signet-ring cell pattern or mucinous cribriform pattern, this case of ALK-rearranged SqCC did not demonstrate such pattern. Instead, the usual morphologic feature of keratinizing pure SqCC that occupied the entire tumor was demonstrated. Furthermore, heterogeneous expression of ALK protein was seen throughout the entire area of the tumor.

Table 1 shows the previously reported 5 cases of ALK-rearranged pure SqCC of the lung, including our case. Recently, non-keratinizing SqCC with ALK rearrangement was reported by Vergne et al. [7] in a never-smoker. On the other hand, cases of keratinizing SqCC with ALK rearrangement were reported by Alrifai et al. [2], Wang et al. [6], and Zhang et al. [8]; one patient was a previous smoker of 40 pack years, whereas two patients were never-smokers. Several authors have reported that ALK rearrangements occurred in tumors with intermediate features between SqCC and adenocarcinoma, such as adenosquamous or mucoepidermoid carcinomas $[11,12]$. In this case, we emphasized that ALK rearrangement can occur in a patient with prior smoking history and who develops ordinary keratinizing SqCC, although the specific ALK fusion partner is unknown.

\section{Detection of ALK-protein by IHC analysis as a convenient ALK screening for lung SqCCs}

Vergne et al. [7] discussed in his report that ALK screening may be relevant for tumors with intermediate phenotypes between SqCC and adenocarcinomas and/or those arising in non-smokers. In his report, he presented a case with non-keratinizing SqCC morphology that expressed CK5/6, p63, and p40, which are classic hallmarks of lung SqCC, and CK7, which is more commonly expressed in lung adenocarcinomas. As mentioned above, it remains unclear which SqCC patients should undergo ALK-testing target in the NCCN guidelines. Considering the relatively high cost of ALK testing by FISH, the position of the NCCN guideline on ALK testing may be sound.

In this case, IHC complemented the detection of ALK rearrangement by FISH. In all previously reported ALK-rearranged SqCC cases, except one that did not undergo IHC (Table 1), ALK protein expression was demonstrated on IHC. This led to the understanding that detection of the ALK protein by IHC analysis may be more suitable for screening of ALK-rearranged lung SqCC, because of its low cost and convenience. Furthermore, since ALK rearrangement may exist in both keratinizing and non-keratinizing pure SqCC, regardless of smoking status, we suppose that ALK screening by IHC may be applicable to all postoperative recurrence or advanced lung SqCCs. We consider that this may increase the probability of ALK-targeted treatment as an option for post-operative recurrence or advanced ALK-rearranged SqCCs of the lung.

Treatment of ALK-rearranged lung adenocarcinoma with the ALK-targeted agent crizotinib is now widely recognized to significantly improve clinical outcomes [9]. Three of the five previously reported cases [6-8] of ALK-rearranged pure SqCCs received crizotinib and markedly responded in terms of improved quality of life (Table 1). These findings strongly support the idea that ALK-testing and subsequent ALK-targeted treatment may be a viable treatment option for patients with post-operative recurrence or advanced lung SqCC. In our patient, it may be possible that ALK-targeted therapy may be beneficial in case of recurrence after radical surgery and adjuvant chemotherapy considering the previously reported cases.

However, it remains unclear whether ALK-positive lung SqCC patients will show a marked response to ALK-targeted therapy that is as good as that of ALK-positive lung adenocarcinoma patients. In the field of molecular-targeted therapy against lung cancer, EGFRtyrosine kinase inhibitors (TKIs) have been reported to be effective for non-adenocarcinoma NSCLC or squamous NSCLC. In a retrospective investigation by Shukuya et al. [13], gefitinib was less effective in non-adenocarcinoma NSCLC harboring EGFR mutations than in adenocarcinoma harboring EGFR mutations. On the other hand, Paik et al. [14] reported that the response to erlotinib in 13 patients with EGFR-mutant squamous NSCLC was comparable to that seen in patients with conventional adenocarcinomas. Further similar studies are necessary to determine the efficacy of ALK-targeted therapy for lung SqCCs.

\section{References}

1. Soda M, Choi YL, Enomoto M, Takada S, Yamashita $Y$, et al. (2007) Identification of the transforming EML4-ALK fusion gene in non-small-cell lung cancer. Nature 448: 561-566.

2. Alrifai D, Popat S, Ahmed M, Gonzalez D, Nicholson AG, et al. (2013) A rare case of squamous cell carcinoma of the lung harbouring ALK and BRAF activating mutations. Lung Cancer 80: 339-340.

3. Takanashi Y, Tajima S, Matsuura S, Koyama S, Takahashi T, et al. (2015) ALK rearranged squamous cell carcinoma of the lung. Respirol Case Rep 3: 105107.

4. Wang J, Shen Q, Shi Q, Yu B, Wang X, et al. (2014) Detection of ALK protein 
Citation: Takanashi Y, Tajima S, Hayakawa T, Takahashi T, Neyatani H, et al. (2016) ALK Rearrangement in Keratinizing Squamous Cell Lung Carcinoma: Immunohistochemistry of ALK-protein as a Convenient ALK Screening. J Pulm Respir Med 6: 316. doi:10.4172/2161-105X.1000316

expression in lung squamous cell carcinomas by immunohistochemistry. J Exp Clin Cancer Res 33: 109

5. Caliò A, Nottegar A, Gilioli E, Bria E, Pilotto S, et al. (2014) ALK/EML4 fusion gene may be found in pure squamous carcinoma of the lung. $J$ Thorac Oncol 9: 729-732.

6. Wang $Q, H e ~ Y$, Yang $X$, Wang $Y$, Xiao H1 (2014) Extraordinary response to crizotinib in a woman with squamous cell lung cancer after two courses of failed chemotherapy. BMC Pulm Med 14: 83.

7. Vergne F, Quéré G, Andrieu-Key S, Descourt R, Quintin-Roué I, et al. (2016) ALK-rearranged squamous cell lung carcinoma responding to crizotinib: A missing link in the field of non-small cell lung cancer? Lung Cancer 91: 67-69.

8. Zhang Q, Wang J, Zhang S (2015) ALK-rearranged squamous cell lung cancer: a case report. Int J Clin Exp Pathol 8: 2195-2198.

9. http://www.nccn.org/professionals/physician_gls/pdf/nscl.pdf.
10. Wong DW, Leung EL, Wong SK, Tin VP, Sihoe AD, et al. (2011) A novel KIF5BALK variant in nonsmall cell lung cancer. Cancer 117: 2709-2718.

11. Chaft JE, Rekhtman N, Ladanyi M, Riely GJ (2012) ALK-rearranged lung cancer: adenosquamous lung cancer masquerading as pure squamous carcinoma. J Thorac Oncol 7: 768-769.

12. Wong DW, Leung EL, So KK, Tam IY, Sihoe AD, et al. (2009) The EML4 ALK fusion gene is involved in various histologic types of lung cancers from nonsmokers with wild-type EGFR and KRAS. Cancer 115: 1723-1733.

13. Shukuya T, Takahashi T, Kaira R, Ono A, Nakamura Y, et al. (2011) Efficacy of gefitinib for non-adenocarcinoma non-small-cell lung cancer patients harboring epidermal growth factor receptor mutations: a pooled analysis of published reports. Cancer Sci 102: 1032-1037.

14. Paik PK, Varghese AM, Sima CS, Moreira AL, Ladanyi M, et al. (2012) Response to erlotinib in patients with EGFR mutant advanced non-small cell lung cancers with a squamous or squamous-like component. Mol Cancer Ther 11: $2535-2540$ 